\title{
BENCANA ALAM DI WILAYAH INDONESIA DARI MASA PRASEJARAH HINGGA MASA KLASIK: SEBUAH TINJAUAN GEOLOGI \& GEOMITOLOGI
}

\author{
Natural Disasters in Indonesian Region During Prehistorical and Classical Periods: \\ A Geological \& Geomythological Perspective
}

\author{
Eko Yulianto \\ Pusat Penelitian Geoteknologi, Lembaga Ilmu Pengetahuan Indonesia \\ Jalan Sangkuriang, Bandung 40135 \\ E-mail: eko.yulianto@lipi.go.id
}

\begin{abstract}
Indonesian region is situated in an active tectonic area due to the interaction of three large plates, namely the Eurasian Plate, the Indo-Australian Plate and the Pacific Plate. The interaction of these three plates causes earthquakes, tsunamis, and volcanic eruptions to occur frequently in Indonesian region. These natural events may have influenced human groups and their civilizations. However, written records of earthquakes, tsunamis and volcanic eruptions in Indonesia were short and only recorded up to about 400 years ago. In fact, natural disasters with large magnitudes generally have a long recurrence time of more than 500 years. As a result, in areas with a short historical time span, it is difficult to find written records of natural disasters that occurred before modern times. Revealing evidence in the soil and rocks using geological methods is an option to find out the phenomena. Humans also recorded past natural events in an unwritten manner. Humans always crave a sense of security physically and psychologically from events that frighten or threaten their lives. Human perceptions of the events they experience are always explained and recorded on the basis of their religions and beliefs and are then manifested in the cultural forms and traditional knowledge. From this perspective, every traditional knowledge and culture is a collective memory of the events that have been experienced by a group of human beings who created that knowledge and culture. This memory can be analyzed and reconstructed to reveal the natural phenomena. From about $100 \mathrm{kyr}$ BP to the Classical Period there were several major natural events that were recorded geologically and may have influenced human civilization in Indonesian region, namely the Toba Caldera Eruption, Maninjau Caldera Eruption, Ranau Caldera Eruption, Masurai Caldera Eruption, Batur Caldera Eruption, Proto Krakatau Eruption and Tsunami, The Samalas eruption, as well as the South Java Earthquake and Tsunami.
\end{abstract}

Keywords: Disaster, unwritten record, Toba, Masurai, Maninjau, Ranau, Batur, Samalas, Proto Krakatau, South Java Tsunami

\begin{abstract}
Abstrak
Indonesia berada di wilayah tektonik aktif karena berada di pertemuan tiga lempeng besar, yaitu Lempeng Eurasia, Lempeng Indo-Australia, dan Lempeng Pasifik. Interaksi ketiga lempeng ini menyebabkan gempabumi, tsunami, letusan gunungapi sering terjadi di wilayah Indonesia. Ketika manusia hadir di wilayah Indonesia, peristiwa-peristiwa alam ini mungkin telah mempengaruhi kelompok-kelompok manusia dan peradabannya. Namun, rekaman tertulis peristiwa gempabumi, tsunami dan letusan gunungapi di wilayah Indonesia hanya terekam hingga sekitar 400 tahun silam. Padahal bencana alam bermagnitudo besar umumnya memiliki waktu perulangan panjang bahkan lebih dari 500 tahun. Akibatnya, di wilayah-wilayah dengan rentang waktu sejarah pendek, bencana alam yang terjadi sebelum masa modern sulit
\end{abstract}


ditemukan rekamannya secara tulisan. Metode untuk mengetahuinya adalah dengan membaca rekaman yang tidak tertulis berupa bukti-bukti di dalam tanah dan batuan. Manusia juga mencatat peristiwa alam di masa lalu secara tidak tertulis. Hal-hal tersebut terjadi karena manusia selalu mendambakan rasa aman secara fisik dan secara psikologis dari peristiwa yang menakutkan atau mengancam keselamatannya. Persepsi manusia terhadap kejadian yang dialaminya selalu dijelaskan dan dicatat berbasiskan kepada agama dan kepercayaan yang dianut oleh masyarakat yang mengalaminya dan kemudian terejawantahkan dalam bentuk pengetahuan tradisional dan budaya, baik benda maupun tak benda. Dari sudut pandang ini, setiap pengetahuan tradisional dan budaya adalah rekaman kolektif atas peristiwa-peristiwa yang telah dilalui oleh sekelompok manusia pencipta budaya itu. Rekaman bisa dibedah dan direkonstruksi ulang, kemudian dikembalikan lagi ke jalan cerita yang sebenarnya. Dalam rentang 100 ribu tahun hingga Masa Klasik terdapat beberapa peristiwa alam besar yang terekam secara geologi dan mungkin berpengaruh pada peradaban manusia di wilayah Indonesia yaitu Letusan Kaldera Toba, Letusan Kaldera Maninjau, Letusan Kaldera Ranau, Letusan Kaldera Masurai, Letusan Kaldera Batur, Letusan dan Tsunami Proto Krakatau, Letusan Samalas, serta Gempabumi dan Tsunami Selatan Jawa.

Kata kunci: Bencana, rekaman tidak tertulis, Toba, Masurai, Maninjau, Ranau, Batur, Samalas, Proto Krakatau, Tsunami Selatan Jawa

\section{PENDAHULUAN}

Secara geografi, wilayah Indonesia adalah sebuah benua maritim yang berada di sekitar garis katulistiwa, di antara Samudera Pasifik dan Samudera India, dan diapit oleh Benua Australia dan Benua Asia. Akibatnya, wilayah Indonesia memiliki suhu yang hangat dan kelembaban serta curah hujan yang tinggi sepanjang tahun. Secara geologi, wilayah Indonesia terbentuk oleh interaksi Lempeng Samudera Indo-Australia, Lempeng Samudera Pasifik, dan Lempeng Benua Eurasia. Interaksi antarketiga lempeng tersebut melahirkan deretan gunungapi, bukan hanya di atas pulau-pulaunya tetapi juga di dalam lautnya. Pelapukan dari produk letusan gunungapi menghasilkan tanah subur yang menumbuhkan hutan hujan tropis dengan beragam sumber makanan di dalamnya sehingga membentuk ekosistem kehidupan yang sangat kaya. Magma yang naik ke permukaan bumi saat pembentukan gunungapi membawa dan mengendapkan berbagai sumberdaya mineral di atau di dekat permukaan bumi. Panas dari magma tersebut memfasilitasi pematangan minyak dan gas bumi. Melimpahnya sumberdaya alam ini menjadi daya tarik bagi manusia untuk menetap dan atau mencari sumber penghidupan. Ini terjadi sejak jutaan tahun yang lalu hingga saat ini. Proses inilah yang membentuk keberagaman genetik di dalam tubuh ras-ras manusia yang tinggal di Wilayah Indonesia pada saat ini (Mona et al., 2009). 


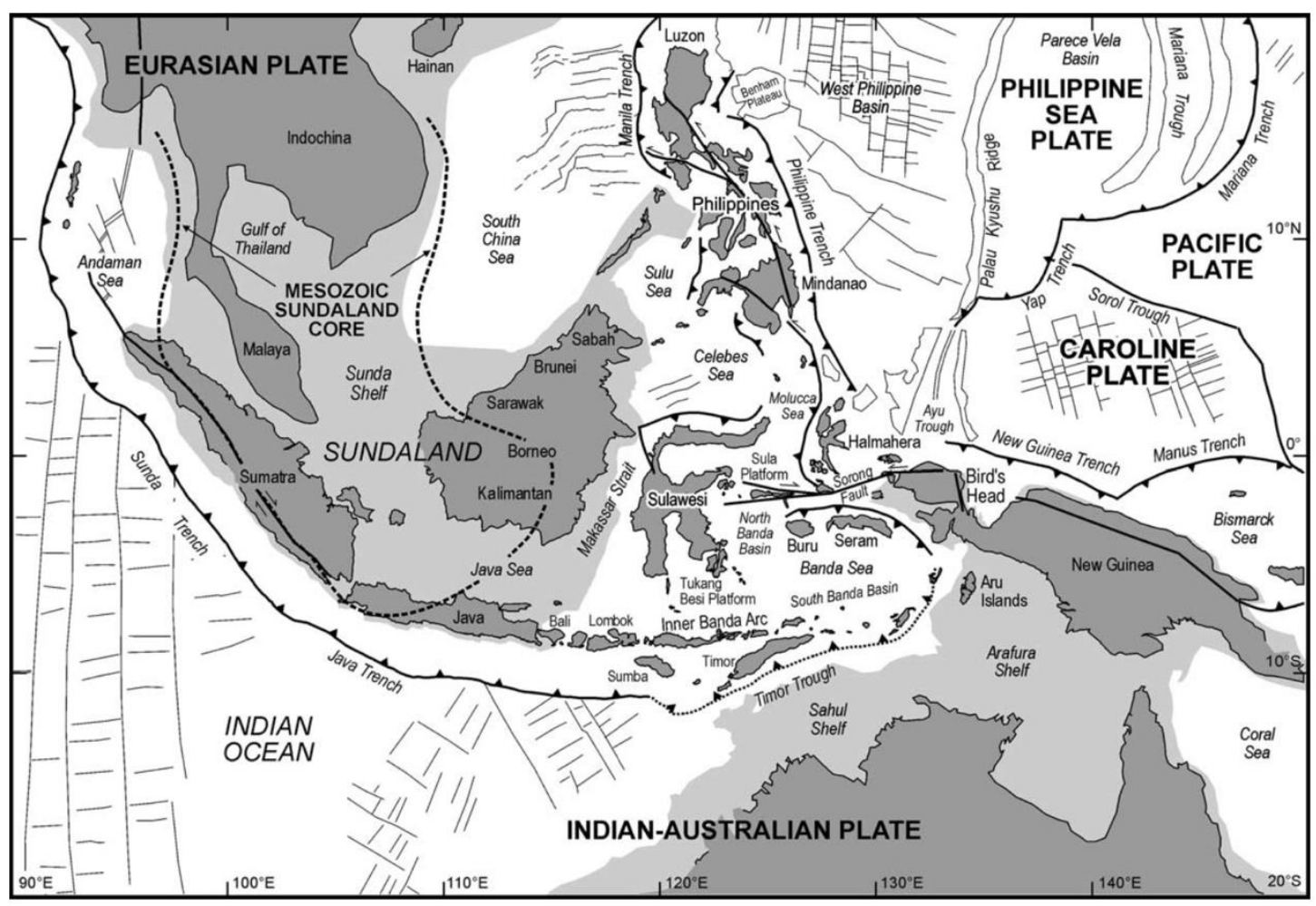

Gambar 1. Peta tektonik wilayah Indonesia, memperlihatkan posisi kepulauan Indonesia dalam konstelasi dengan Lempeng India-Australia, Lempeng Eurasia dan Lempang Pasifik. Konstelasi ini menjadikan Indonesia menjadi salah satu wilayah yang sangat aktif secara tektonik (after Hall, 2002).

Pada sisi lain, interaksi antar Lempeng Eurasia, Lempeng Indo-Australia, dan Lempeng Pasifik (Gambar 1) mengakibatkan wilayah Indonesia menjadi salah satu wilayah dengan aktivitas tektonik yang paling aktif di dunia (Hamilton, 1979). Aktivitas tektonik ini mengakibatkan gempabumi, tsunami dan letusan gunungapi sering terjadi di wilayah Indonesia bahkan dari sebelum keberadaan manusia. Sejak hadirnya manusia dan peradabannya di bumi, fenomena-fenomena alam ini seringkali mengakibatkan timbulnya bencana, bahkan mengakibatkan hilangnya berbagai peradaban di masa lalu, misalnya terkuburnya peradaban Pompeii oleh letusan Gunungapi Vesuvius (Giacomelli et al., 2003). Hancurnya peradaban manusia akibat bencana alam juga menjadi banyak dikisahkan dalam kitab-kitab suci agama-agama di dunia meskipun dinarasikan secara berbeda.

Peradaban manusia sudah muncul di wilayah Indonesia sejak ribuan tahun lalu, tetapi catatan tertulis tentang fenomena bencana alam di wilayah Indonesia baru ada dari sekitar 400 tahun silam, yaitu ketika orang-orang eropa mulai ramai di wilayah Indonesia. Ini artinya, catatan tertulis tentang bencana alam yang terjadi di wilayah Indonesia hanya merekam kejadian bencana pasca-Masa Klasik. Ada beberapa catatan tertulis lebih tua namun bersifat sporadis, seperti catatan tentang gunung meletus dan gempa bumi dalam Kitab Negarakertagama (Mulyana, 1979). Padahal fenomena 
bencana alam bermagnitudo besar yang dapat menghancurkan peradaban manusia di masa lalu umumnya memiliki waktu perulangan lebih dari 500 tahun. Gempa yang memicu tsunami Aceh 2004 misalnya secara kalkulasi hipotetik memiliki perulangan 525 tahun (MacCaffrey, 2008). Dari penelitian lapisan paleotsunami di bawah lapisan tsunami 2004, tsunami sebelum 2004 terjadi antara 550 hingga 750 tahun lalu (Jankaew et al, 2008). Gempa Tohoku 2011 sebelumnya pernah terjadi di tahun 869 atau sekitar 1142 tahun lalu (Minoura et al., 2001). Akibatnya, di wilayah Indonesia yang memiliki rentang waktu sejarah yang pendek, bencana alam secara umum dan khususnya yang bermagnitudo besar tidak akan pernah ditemukan rekaman tertulis. Satu-satunya jalan untuk mengetahuinya adalah dengan membuka rekaman-rekaman yang bukan berupa tulisan, salah satunya adalah rekaman geologi.

Setiap peristiwa selalu meninggalkan bekas atau bukti. Dalam konteks buktibukti yang tidak tertulis terhadap peristiwa gempabumi, tsunami, dan letusan gunungapi di masa lalu, saintis kebumian dari waktu ke waktu terus menciptakan inovasi dan invensi metode dan teknologi guna membaca bukti-bukti yang terekam di dalam bebatuan bumi. Pendekatan matematika, kimia, fisika, biologi diaplikasikan dalam ranah geologi. Metode-metode tersebut semakin lama semakin beragam, akurat, presisi dan murah. Dengan demikian, meskipun catatan tertulis tentang peristiwa alam di masa lalu tidak ada atau tidak ditemukan, kejadian-kejadiannya dalam rentang waktu yang sangat panjang tetap dapat diketahui melalui pembacaan rekaman yang tersimpan di dalam bumi. Namun, peristiwa bencana tidak mungkin didokumentasikan secara utuh jika hanya dilihat dari sudut pandang geologi. Studi geologi hanya dapat mengungkapkan karakteristik sumber ancaman (hazard) saja. Studi geologi tidak dapat mengungkapkan dampak dari ancaman itu terhadap manusia dan peradabannya. Oleh karena itu, studi terhadap peristiwa bencana di masa lalu perlu dilakukan dengan pendekatan interdisiplin atau setidaknya multidisiplin. Dalam konteks inilah pendekatan geoarkeologi dan geomitologi memperoleh relevansinya.

Sejak setidaknya 100 ribu tahun lalu hingga Masa Klasik, berbagai peristiwa gempabumi, tsunami dan letusan gunungapi bermagnitudo besar yang terjadi di wilayah Indonesia terekam dengan baik di dalam tanah dan batuan. Dalam rentang waktu itu, pulau-pulau di wilayah Indonesia sudah dihuni oleh manusia. Jika diasumsikan peristiwa gempabumi, tsunami dan letusan gunungapi bermagnitudo besar memiliki waktu perulangan kejadian 1000 tahun maka kelompok-kelompok manusia itu sudah mengalami puluhan bahkan ratusan kali bencana. Mengingat ada ratusan gunungapi aktif di wilayah Indonesia, letusan-letusan bermagnitudo besar boleh jadi telah berulangkali mengubur peradaban manusia yang ada di lereng-lerengnya yang subur. Ratusan gempabumi dan tsunami bermagnitudo besar boleh jadi juga telah berulangkali meluluhlantakkan peradaban manusia di dataran-dataran pantai. Maka perulangan ancaman alam itu dapat dipastikan sangat mempengaruhi kehidupan manusia dan peradabannya serta berkontribusi dalam membentuk budaya dari kelompok-kelompok manusia yang ada di Indonesia. 
Paper ini memaparkan berbagai rekaman geologi atas berbagai peristiwa ancaman dan bencana alam di masa lalu tersebut. Pemaparan ini diharapkan dapat memberikan orientasi terhadap studi-studi arkeologi, geoarkeologi dan geomitologi di wilayah Indonesia di masa mendatang.

\section{METODE}

Studi ini dilakukan dengan pendekatan review. Peristiwa alam yang ditinjau dalam studi ini yaitu letusan gunungapi, gempabumi dan tsunami. Tinjauan difokuskan pada rentang waktu Masa Prasejarah hingga Masa Klasik di wilayah Indonesia. Data tersebut dikumpulkan, digabungkan, disusun, dikombinasikan, dan diperiksa dengan seksama dari berbagai perspektif untuk mendapatkan gambaran tentang aspek-aspek geoarkeologi bencana dan geomitologi secara umum. Hasil studi merupakan simpulan yang ditarik dari kesesuaian antara aspek-aspek geologi yang diduga berkaitan dengan konteks arkeologi. Hasil studi ini merupakan pandangan yang bersifat etik atau diambil dari sudut pandang peneliti.

\section{BENCANA DALAM LINTASAN MASA PRASEJARAH HINGGA MASA KLASIK}

\section{Letusan Gunungapi}

Wilayah Asia Tenggara terbentuk akibat proses subduksi antara lempeng samudera Indo-Australia dengan lempeng benua Eurasia sejak puluhan juta tahun lalu (Hall et al., 1996). Proses inilah yang melahirkan deretan gunungapi sebagai bagian dari rantai gunung api yang mengelilingi Samudera Pasifik (Circum Pasific). Zaman Kuarter yang dimulai dari sekitar 2 juta tahun lalu ditandai salah satunya oleh peningkatan aktivitas gunungapi di seluruh dunia. Pada saat yang bersamaan, Kepulauan Indonesia sudah terbentuk hampir mendekati wujud dan posisinya seperti saat ini sejak sekitar 2 juta tahun yang lalu (Hall et al., 1996). Deretan gunungapi di Indonesia yang sekarang masih tergolong gunungapi aktif, banyak diantaranya yang mulai beraktivitas di permulaan Zaman Kuarter ini. Namun, informasi tentang letusan gunungapi dalam rentang waktu Plistosen masih sangat sedikit. Hasil-hasil penelitian gunungapi di seluruh dunia khususnya terkait informasi tentang waktu terjadinya letusan secara akurat, sebagaian besar adalah peristiwa letusan yang terjadi pada Kala Holosen (Simkin dan Siebert, 2000).

Selama Kala Holosen terdapat 7.742 letusan gunungapi di Asia Tenggara (De Maisonneuve \& Bergal-Kuvikas, 2020). Ini mencakup 75\% dari total letusan gunungapi yang ada di seluruh dunia. Dari jumlah itu, 90\% diantaranya merupakan letusan dengan VEI (Volcanic Explosivity Index) kurang dari 3. Terdapat setidaknya 15 letusan dengan VEI 6-8, 12 diantaranya adalah gunungapi di wilayah Indonesia (Gambar 2) yaitu Toba (73,5 ka, 502 ka dan 792 ka), Maninjau (52 ka), Masurai (33 ka), Ranau (34 ka), Krakatau (535 M, 1883), Batur (24 \& 35 ka), Samalas (1257 M) dan Tambora (1815 
M). Dasyatnya letusan Krakatau, Samalas, dan Tambora juga ditunjukkan oleh terekamnya letusan itu di dalam lapisan aerosol dalam lapisan tudung es yang ada baik di lapisan-lapisan es di kutub utara dan selatan bumi (Sigl et al., 2015). Letusan besar gunungapi yang berada di belahan utara, abu dan gas-gas aerosolnya diendapkan di kutub utara bumi. Sementara letusan besar gunungapi yang berada di belahan selatan, abu dan gas-gas aerosolnya diendapkan hingga kutub selatan bumi. Berdasarkan jejak abu dan gas-gas aerosol yang tertinggal di kedua kutub bumi disertai pentarihkan umur terhadap lapisan-lapisannya, kejadian letusan-letusan besar gunungapi di masa lalu dapat dilacak sumber dan waktu terjadinya letusan-letusan itu (Gambar 3).

Namun, letusan gunungapi-gunungapi lain dengan VEI lebih dari 5 boleh jadi ada yang belum teridentifikasi dan dimasukkan di dalam data statistik tersebut. Hal ini disebabkan oleh masih sedikitnya penelitian tentang letusan-letusan gunungapi selama rentang prasejarah di Indonesia. Diantara letusan purba bermagnitudo besar yang mungkin pernah terjadi adalah letusan Gunung Sunda Purba sekitar 200 ribu tahun lalu. Letusan ini diduga menghasilkan kaldera yang ditengahnya kemudian muncul gunungapi baru yaitu Gunung Tangkubanparahu.

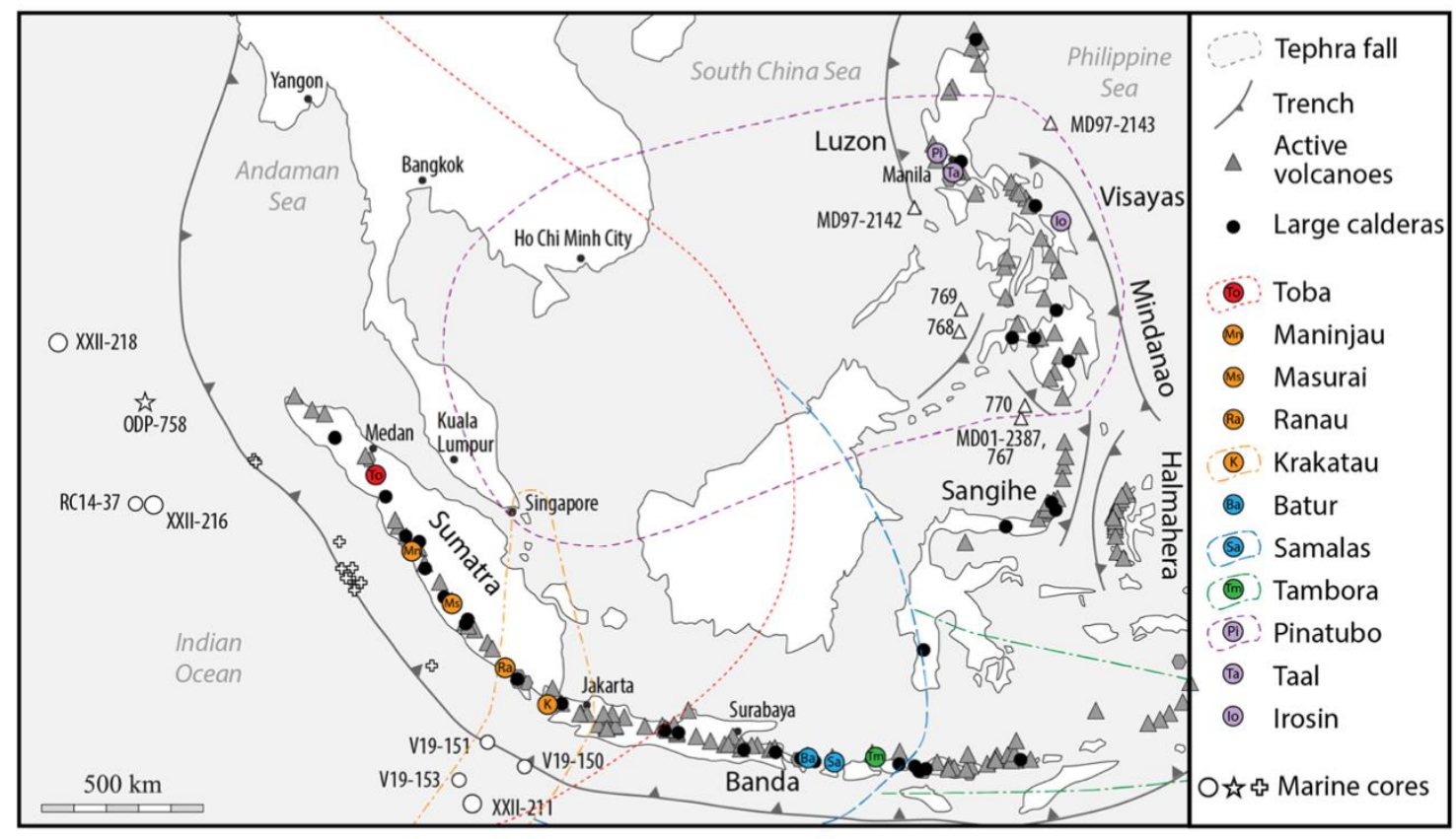

Gambar 2. Peta memperlihatkan sebaran gunungapi di Asia Tenggara yang pernah meletus dengan VEI lebih dari 5 (after De Maisonneuve, C.B and Bergal-Kuvikas, O. 2020). Dari 15 kejadian letusan besar, 12 letusan terjadi di Indonesia.

\section{Gempabumi}

Secara statistik, peristiwa gempabumi lebih sering terjadi di Indonesia jika dibandingkan dengan letusan gunungapi dan tsunami. Frekuensi rata-rata kejadian gempabumi merusak di Indonesia dari tahun 1900 hingga tahun 2012 adalah sekali 
setiap 167,77 hari atau 5,6 bulan sekali (Parwanto \& Oyama, 2014). Catatan tertulis tentang gempabumi yang terjadi selama masa Prasejarah dan Masa Klasik masih sangat sedikit jumlahnya. Dua diantaranya tercatat di dalam Serat Pararaton (van Der Meer, 1974; Brandes, 1920) dan Babad Galuh (Wahyu, 2009). Beberapa informasi tidak tertulis dan agak kabur tentang kejadian gempabumi dari sebelum hingga Masa Klasik yang bersumber dari legenda tercatat secara singkat di dalam Catalogue Wichmann (Wichmann, 1918). Gempabumi itu terjadi pada tahun 134, 296, 416, 1296, 1450, 1500, 1578, 1584, 1586 M di Jawa dan 416 M di Sumatera.

\section{Tsunami}

Lebih dari $90 \%$ peristiwa tsunami yang terjadi di Indonesia dari tahun 1600 hingga 1998 dipicu oleh gempabumi (Hamzah et al., 2000). Sementara itu, frekuensi rata-rata kejadian tsunami merusak di Indonesia dari tahun 1900 hingga tahun 2012 adalah sekali dalam 490,71 hari atau 1 tahun 4 bulan (Parwanto \& Oyama, 2014). Bahkan secara statistik, gempa berskala lebih besar dari $9(\mathrm{M}>9,0)$ yang mampu memicu tsunami raksasa berulang setiap setidaknya 525 tahun sekali di zona subduksi sebelah barat Sumatera dan 675 tahun sekali di sepanjang zona subduksi di selatan Jawa hingga Nusa Tenggara (MaccAffrey, 2008). Dari ketiga informasi itu dapat diduga bahwa dari ribuan tahun lalu, kelompok-kelompok manusia yang menghuni wilayahwilayah Indonesia khususnya di dataran pantai sudah sering mengalami peristiwa tsunami. Catatan tertulis tentang peristiwa tsunami selama Masa Prasejarah hingga Masa Klasik hampir tidak dapat ditemui. Catalogue Wichmann (Wichmann, 1918) mencatat informasi samar-samar yang boleh jadi berkaitan dengan tsunami yang terjadi pada tahun $416 \mathrm{M}$.

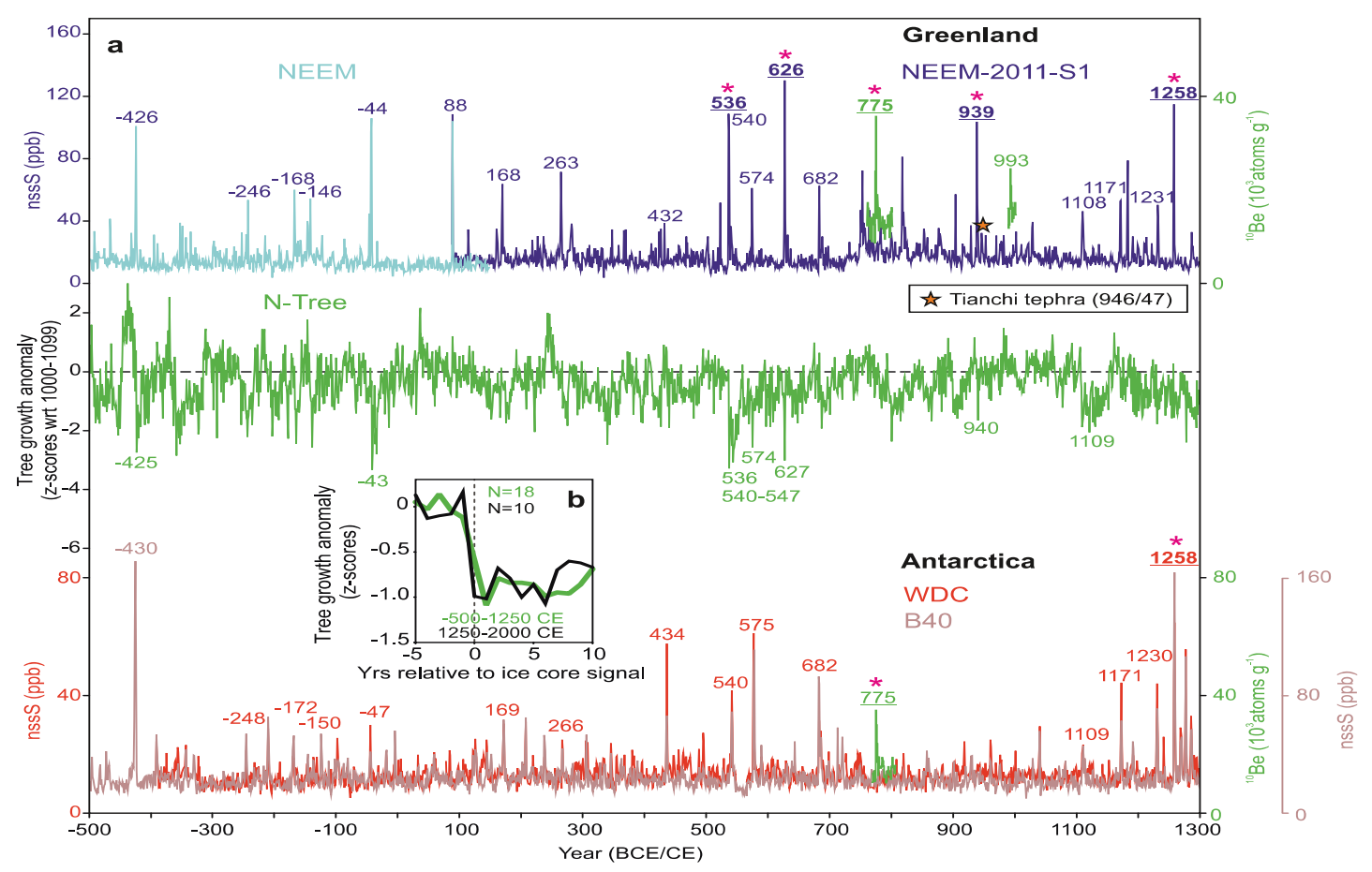


Gambar 3. Kurva kandungan sulfat di dalam inti es dari wilayah kutub utara (Greenland) dan kutub selatan (Antartica) serta anomali pertumbuhan lingkaran pohon (after Sigl et al., 2015). Perhatikan puncak-puncak sulfat dan lingkaran pohon pada kisaran waktu 535-540 M yang mungkin berkaitan dengan letusan Proto Krakatau, dan kisaran waktu 1258 M yang berkaitan dengan letusan Gunung Samalas.

\section{DISKUSI}

\section{Pengaruh Letusan Besar Terhadap Manusia dan Peradaban Masa Prasejarah}

Hadirnya lapisan-lapisan tuf di dalam formasi-formasi batuan pengandung fosil manusia purba di Sangiran yaitu Formasi Pucangan dan Kabuh (Itihara et al., 1994) mengindikasikan bahwa bahkan kehidupan manusia purba pun kemungkinan tidak lepas dari pengaruh letusan gunungapi. Lapisan-lapisan tuf itu diduga sebagai produk letusan Proto Gunung Lawu yang pada saat itu posisi kawahnya diduga masih berada di sebelah utara dari posisi kawah modernnya.

Letusan Toba 792 dan 502 ka dan letusan Gunung Sunda Purba 200 ka terjadi dalam rentang pengendapan Formasi Pucangan dan Kabuh. Oleh karena itu, secara spekulatif dapat diduga bahwa lingkungan kehidupan manusia Purba di Sangiran disamping dipengaruhi oleh aktivitas volkanisme lokal (Proto Gunung Lawu) boleh jadi juga dipengaruhi oleh aktivitas letusan Toba dan Sunda Purba tersebut. Adanya kemungkinan pengaruh itu diindikasikan oleh hadirnya lapisan Tuf Tengah Formasi Kabuh/Bapang berumur 780 ka berdasarkan pentarikhan umur menggunakan metode Jejak Bilah (Itihara et al., 1994). Spekulasi ini juga memicu pertanyaan lain yaitu tentang kemungkinan lapisan Tuf Atas di Formasi Kabuh/Bapang adalah produk letusan Toba $502 \mathrm{ka}$.

Rentang waktu Plistosen Tengah-Atas berkaitan erat dengan evolusi awal manusia di wilayah Indonesia. Sementara letusan-letusan bermagnitudo besar yang sudah diketahui berlangsung pada rentang waktu 50 hingga $20 \mathrm{ka}$ tahun lalu. Oleh karena itu, patut diduga bahwa kehidupan manusia prasejarah di wilayah Indonesia sangat dipengaruhi oleh letusan-letusan itu baik langsung maupun tidak langsung. Letusan Toba 73,5 ka misalnya, secara langsung mungkin telah mengubur situs-situs tinggalan prasejarah di sekitar Danau Toba. Pada sisi lain, letusan ini diduga telah memicu fenomena bottle-neck dalam evolusi manusia (Rampino \& Self, 1992; Williams et al., 2009). Hal ini diduga dipicu oleh terjadinya perubahan iklim sebagai akibat dari letusan itu. Letusan gunungapi dengan magnitudo besar selalu melontarkan abu dan gas-gas aerosol dalam volume sangat besar hingga beberapa puluh kilometer ke bagian atas atmosfer bumi. Produk-produk ini kemudian terdistribusi dan menyelimuti ke seluruh atau sebagian atmosfer bumi akibat adanya sirkulasi udara atmosferik. Selimut abu dan gas ini dapat berada di atmosfer selama beberapa tahun dan secara perlahan-lahan turun dan mengendap di permukaan bumi. Ketika masih berada di atmosfer, abu dan gas-gas aerosol itu dapat menghalangi sinar matahari sehingga mengakibatkan turunnya suhu atmosfer bumi. Penurunan suhu bumi ini dapat mengubah pola cuaca di seluruh atau sebagian permukaan bumi (Jones et al., 2005; 
Jones et al., 2007). Jika letusan Toba 73,5 ka yang lalu memiliki dampak yang luar biasa terhadap lingkungan dan manusia maka letusan-letusan besar pada periode 50-20 ka yang lalu kemungkinan juga memiliki dampak yang juga signifikan terhadap kehidupan manusia dan peradabannya.

\section{Pengaruh Letusan Besar Terhadap Manusia dan Peradaban Masa Klasik}

Satu-satunya letusan besar gunungapi pada Masa Klasik dicatat dalam Wichmann Catalogue (Wichmann, 1918), terjadi pada tahun 416 M atau 338 Saka. Catatan ini bersumber dari Kitab Pustaka Raja Purwa karya Ronggowarsito yang mengisahkan peristiwa gempabumi di Jawa dan Sumatra akibat letusan hebat Gunung Kapi (Proto Krakatau ?). Gunung Kapi akhirnya runtuh dan menghilang di kedalaman bumi. Air laut membanjiri wilayah-wilayah di sebelah timur Gunung Kamula di timur dan di sebelah barat hingga Raja Basa. Kisah ini beraroma mitos sangat kuat. Namun kisah ini boleh jadi berkaitan dengan teori dari David Keys tentang terjadinya letusan proto Gunung Krakatau yang terjadi di tahun 535 M (Keys, 2000). Menurut Keys, data lingkaran pohon dan bukti sejarah menunjukkan indikasi-indikasi yang jelas terjadinya kekacauan iklim dunia pada periode setelah tahun 535 M. David Keys memverifikasi dan mendokumentasikan perubahan-perubahan politik dan keagamaan dunia yang mengakibatkan abad Kegelapan (Dark-Ages) yang diduga dipicu atau setidaknya berkaitan dengan letusan Proto-Krakatau tersebut. Menurut Keys, letusan ini berkorelasi dengan lenyapnya sejumlah kerajaan-kerajaan di Sumatera dan Jawa serta munculnya kerajaan-kerajaan baru di kedua tempat itu setelahnya. Meskipun hingga saat ini belum ada penelitian geologi yang melaporkan bukti-bukti letusan hebat yang berkaitan dengan aktivitas Proto-Krakatau, kedekatan kisah dan waktu yang tercatat dalam Kitab Pustaka Raja Purwa dengan teori yang disodorkan oleh David Keys tidak tertutup kemungkinan ada kaitannya.

\section{Tefrokronologi Sebagai Lapisan Kunci Dalam Studi Arkeologi}

Tefrokronologi adalah penentuan kronologi yang didasarkan pada karakteristik lapisan-lapisan tuf piroklastik yang dihasilkan oleh letusan gunungapi. Setiap letusan menghasilkan mineral gelas amorf yang memiliki indeks refraksi yang berbeda-beda. Indeks refraksi ini menjadi seperti sidik jari bagi setiap lapisan tufa atau tefra itu. Jika indeks refraksi dan umur lapisan-lapisan tuf hasil letusan besar gunungapi dapat diketahui maka lapisan-lapisan budaya prasejarah pada rentang waktu setara dapat ditentukan umur relatifnya berdasarkan pada indeks refraksi lapisan tufa yang ditemukan. Dari perspektif ini, mengetahui indeks refraksi dari lapisan tuf Toba (792, 502, 73,5 ka), Maninjau (52 ka), Masurai (33 ka), Ranau (34 ka), Krakatau (535 M), Batur (24 \& $35 \mathrm{ka})$, Samalas $(1257 \mathrm{M})$ adalah hal penting dalam kaitannya dengan studi-studi arkeologi prasejarah di Indonesia. Ini karena lapisan-lapisan tuf tersebut tersebar secara regional sehingga dapat digunakan sebagai lapisan kunci baik untuk 
menentukan umur relatif lapisan budaya maupun untuk membuat korelasi kronologi antar lapisan budaya di suatu tempat dengan tempat lainnya.

\section{Geomitologi Bencana}

Karena manusia modern (Homo sapiens sapiens) sudah menghuni wilayah Indonesia sejak puluhan ribu tahun yang lalu maka sudah puluhan ribu tahun pula manusia-manusia tersebut berinteraksi dengan lingkungan sekitarnya termasuk dengan berbagai jenis bencana secara berulangkali dari generasi ke generasi. Banyak dari peristiwa bencana itu yang telah telah merenggut korban jiwa dan kerugian harta benda. Hal itu juga menimbulkan rasa takut pada manusia karena ada banyak hal dari peristiwa itu yang tidak diketahui dan dipahaminya serta mengancam keselamatan hidupnya. Karenanya, manusia membutuhkan penjelasan-penjelasan yang menenangkan pikirannya. Geomitologi merupakan teori euhemerisme dalam aplikasi-aplikasi geologi (Vitaliano, 1968). Teori euhemerisme (Euhemerus, Sisilia, 300 BC) menyatakan bahwa dewa-dewa mitologi sebenarnya makhluk-makhluk (yang pernah hidup) yang didewakan. Studi geomitologi dilakukan untuk mengembalikan mitos-mitos ke jalan cerita sejarah. Legenda dan mitos yang diciptakan oleh manusia namun manusia penciptanya tidak menyaksikan peristiwa geologi itu, tidak termasuk dalam ranah geomitologi.

Manusia selalu mendambakan rasa aman secara fisik dan secara psikologis (Malinowski, 1948). Dengan kemampuan intelektualnya, manusia mereka-reka penjelasan-penjelasan kausalitas terhadap berbagai peristiwa bencana itu. Penjelasan ini dijadikan sebagai landasan untuk melakukan berbagai tindakan sebagai upaya mengatasi dan menghadapi peristiwa serupa di masa selanjutnya. Lahirlah budaya, baik dalam wujud benda maupun tak benda, yang secara eksplisit dan implisit merekam peristiwa-peristiwa itu. Jadi, budaya pada dasarnya adalah kumpulan pengetahuan tentang cara hidup khususnya cara berinteraksi manusia dengan lingkungan sekitarnya. Pengetahuan ini senantiasa dikumpulkan, diverifikasi dan diuji dari peristiwa ke peristiwa dan dari generasi ke generasi di sepanjang sejarah manusia. Kumpulan pengetahuan ini seringkali selanjutnya bertransformasi menjadi kepercayaan dan agama. Pengetahuan yang sebagian sudah bertransformasi menjadi kepercayaan ini dipraktikan dalam kehidupan manusia dan menjadi pedoman untuk mengatasi berbagai persoalan. Unsur kepercayaan dan agama ini pada akhirnya berperan sebagai "obat penenang" atau semacam psikiatri yang murah namun seringkali mujarab dalam memberikan rasa aman secara psikologis. Itulah mengapa persepsi manusia terhadap kejadian yang dialaminya selalu dijelaskan dan dicatat berbasiskan kepada kepercayaan dan agama yang dianutnya. Peristiwa yang sama akan dijelaskan secara berbeda oleh kelompok manusia yang memiliki latar belakang kepercayaan berbeda. Dari sudut pandang ini, setiap pengetahuan tradisional dan budaya adalah rekaman kolektif atas peristiwa-peristiwa yang telah dilalui oleh sekelompok manusia pencipta budaya itu. 
Oleh karenanya, rekaman ini juga bisa dibedah dan direkonstruksi ulang, kemudian dikembalikan lagi ke jalan cerita yang sebenarnya.

Banyak kisah-kisah mitos dan cerita legenda yang ada di setiap suku-suku di Indonesia. Meskipun kisah-kisah tersebut kadang-kadang terkesan tidak masuk akal, boleh jadi kisah-kisah tersebut merupakan rekaman-rekaman terhadap kejadian bencana di masa lalu. Legenda Sangkuriang dan toponimi-toponimi di Kawasan Lembang misalnya, menurut van Bemmelen merupakan rekaman masyarakat prasejarah Sunda terhadap peristiwa pergerakan Sesar Lembang di masa lalu (van Bemmelen, 1949). Masyarakat Pulau Simeulue mempunyai pengetahuan tradisional Smong yang berperan menyelamatkan banyak nyawa dari tsunami Samudera India 2004 (Yogaswara \& Yulianto, 2006; McAdoo et al., 2006). Sebagian cerita-cerita mitos yang berkaitan dengan gunungapi, gempabumi dan tsunami di Indonesia dengan tsunami, didokumentasikan oleh Arif (2013). Masyarakat Mentawai memiliki legenda Teteu yang berkaitan erat dengan gempabumi dan tsunami (Yulianto et al., 2010). Sebelum peristiwa gempabumi dan liquefaksi di Sulawesi Tengah tahun 2018, masyarakat Suku Kaili sudah memiliki istilah Nalodo untuk menyebut liquefaksi beserta toponimitopinimi yang berkaitan dengan fenomena alam itu (Moerwanto \& Zulfan, 2020). Kisah, mitos, legenda, toponimi dan istilah-istilah yang berkaitan dengan fenomena alam khususnya bencana niscaya ada hampir di setiap suku yang ada di Indonesia. Namun demikian, penelitian multidisiplin secara lebih mendalam perlu dilakukan guna mengungkapkan kaitan cerita-cerita itu dengan peristiwa-peristiwa bencana di masa lalu.

\section{SIMPULAN}

Hubungan antara peristiwa bencana dengan peradaban manusia di Indonesia pada Masa Prasejarah hingga Masa Klasik masih belum banyak dipelajari. Pengaruh bencana alam terhadap perkembangan budaya dan peradaban manusia selama Masa Prasejarah bahkan hingga Masa Klasik belum banyak diketahui. Karena wilayah Indonesia sejak terbentuknya berada di wilayah tektonik aktif yang menghasilkan letusan gunungapi, gempabumi dan tsunami secara berulangkali maka dapat dipastikan bahwa manusia yang menghuni wilayah Indonesia kemungkinan telah berulangkali mengalami kejadian alam itu. Banyak dari kejadian itu yang mungkin telah merusak atau menghancurkan manusia dan peradabannya pada satu sisi. Namun di sisi lain, kejadian-kejadian bencana tersebut kemungkinan besar juga telah ikut andil dalam membentuk peradaban. Meskipun tidak terdapat catatan tertulis, peristiwa-peristiwa bencana dapat terekam dalam bentuk budaya benda dan tak benda. Studi multi dan inter disiplin diperlukan guna mengungkap rekaman tidak tertulis dari peritiwa-peristiwa bencana ini, serta hubungan antara peristiwa-peristiwa bencana dengan perkembangan peradaban manusia di wilayah Indonesia. 


\section{DAFTAR PUSTAKA}

Arif, A. 2013. Ekspedisi Kompas hidup mati di negeri cincin api. Jakarta: Penerbit Buku Kompas.

Brandes, J. L. A. 1920. Pararaton (Ken Arok) of het Boek der Koningen van Tumapel en van Majapahit, VBG 54.1, Batavia/s-Gravenhage, 1897/1920.

De Maisonneuve, C.B and Bergal-Kuvikas, O. 2020. Timing, magnitude and geochemistry of major Southeast Asian volcanic eruptions: Identifying tephrochronologic markers. Journal of Quaternary Science, 35, 272-287.

Giacomelli L., Perrotta A., Scandone R. et al. 2003. The eruption of Vesuvius of 79 AD and its impact on human environment in Pompeii. Episodes, 26, 234-237.

Hall, R., 1996. Reconstructing Cenozoic SE Asia. In: Hall, R., Blundell, D.J. (Eds.), Tectonic Evolution of SE Asia. Geological Society of London Special Publication 106, 153-184.

Hall, R., 2002. Cenozoic Geological and Plate Tectonic Evolution of SE Asia and the SW Pacific: Computer-Based Reconstruction, Model, and Animation. Journal of Asian Earth Science, 20, 353-431.

Hamilton, W. 1979. Tectonics of the Indonesian region. U.S. Geological Survey Prof. Paper 1078.

Hamzah, L. Puspita, N.T. and Imamura, F., 2000, Tsunami catalogue and zones in Indonesia. Journal of Natural Disaster Service, 22(1), 25-43.

Itihara, M., Watanabe, N., Kadar, D., Kumai, H. 1994. Quaternary stratigraphy of the hominid fossil bearing formations in the Sangiran area, Central Java. Courier ForschungsInstitut Senckenberg 171, 123-128.

Jankaew, K., Atwater, B.F., Sawai, Y., Choowong, M., Charoentitirat, T., Martin, M.E., Prendergast, A. 2008. Medieval forewarning of the 2004 Indian Ocean tsunami in Thailand. Nature, Vol. 455.

Jones, G. S., Gregory, J., Stott, P., Tett, S., Thorp, R. 2005. An AOGCM simulation of the climate response to a volcanic super-eruption. Climate Dynamic, 25, 725-738.

Jones, M. T., Sparks, R.S.J., Valdes, P.J. 2007. The climatic impact of supervolcanic ash blankets, Climate Dynamic, 29, 553-564.

Keys, D. 2000. Catastrophe: A Quest for the Origins of the Modern World. New York: Ballantine.

McAdoo, B.G., Dengler, L., Prasetya, G., Titov, V. 2006. Smong: How an oral history saved thousands on Indonesia's Simeulue island during the December 2004 and March 2005 tsunamis. Earthquake Spectra, 22 (S3), S661-69.

MacCaffrey, R. 2008. Global frequency of magnitude 9 earthquakes. Geology 36, 263-266.

Malinowski, O. 1948. Magic, science and religion and other essays. Glencoe, Illinois, and Boston, Massachusetts.

Minoura, K., Imamura, F., Sugawara, D., Kono, Y., Iwashita, T. 2001. The 869 Jogan tsunami deposit and recurrence interval of large-scale tsunami on the Pacific coast of northeast Japan. Journal of Natural Disaster Science, 23(2), 83-88.

Mona, S., Grunz, K.E., Brauer, S., Pakendorf, B., Castri, L., Sudoyo, H., Marzuki, S., Barnes, R.H., Schmidtke, J., Stoneking, M., Kayser, M. 2009. Genetic admixture history of Eastern Indonesia as revealed by Y-chromosome and mitochondrial DNA analysis. Moleculer Biology Evolution 26, 1865-1877.

Moerwanto, A.S. dan Zulfan, J. 2020. Mitigasi bencana alam pada infrastruktur jalan dan jembatan. Jurnal HPJI, 6(1), 1-14.

Parwanto, N.B. and Oyama, T. 2014. A statistical analysis and comparison of historical earthquake and tsunami disasters in Japan and Indonesia. International Journal of Disaster Risk Reduction 7, 122-141.

Mulyana, S. 1979. Nagarakertagama dan tafsir sejarahnya. Bhratara Karya Aksara, Jakarta. 
Rampino, M.R., Self, S. 1992. Volcanic winter and accelerated glaciation following the Toba super-eruption. Nature 359, 50-52.

Sigl, M., Winstrup, M., McConnell, J. R., Welten, K. C., Plunkett, G., Ludlow, F., Buntgen, U., Caffee, M., Chellman, N., Dahl-Jensen, D., Fischer, H., Kipfstuhl, S., Kostick, C., Maselli, O. J., Mekhaldi, F., Mulvaney, R., Muscheler, R., Pasteris, D. R., Pilcher, J. R., Salzer, M., Schupbach, S., Steffensen, J. P., Vinther, B. M., and Woodruff, T. E. 2015. Timing and climate forcing of volcanic eruptions for the past 2,500 years. Nature, 523, 543-549.

Simkin, T. dan Siebert, L. 2000. Earth's volcanoes and eruptions: An overview, in Encyclopedia of Volcanoes, edited by H. Sigurdsson, pp. 249-261, Academic, San Diego, Calif.

Van Bemmelen, R. W. 1949. The Geology of Indonesia vol IA General Geology, Martinus Nijhoff. The Hague, Netherland.

Van der Meer, N.C.G.V.S. 1974. The Development of sawah cultivation in ancient Java (Thesis). ANU, $198 \mathrm{p}$.

Vitaliano, D.B. 1968. Geomythology: The Impact of Geologic Events on History and Legend with Special Reference to Atlantis. Journal of the Folklore Institute, 5(1), 5-30.

Wahyu, A.N. 2009. Waosan Babad Galuh: dari Prabu Ciungwanara hingga Prabu Siliwangi (Naskah Kraton Kasepuhan Cirebon). Penerbit Pustaka, 452 hal.

Wichmann, C E A. 1918. Die Erdbeben des indischen Archipels bis zum Jahre 1857. Amsterdam: Muller.

Williams, M.A.J., Ambrose, S.H., van der Kaars, S., Ruehlemann, C., Chattopadhyaya, U., Pal, J., Chauhan, P.R. 2009. Environmental impact of the 73 ka Toba super-eruption in South Asia. Palaeogeogr Palaeoclimatol Palaeoecol 284, 295-314.

Yogaswara, H. dan Yulianto, E. 2006. Sejarah Smong. UNESCO, Jakarta.

Yulianto, E., Kusmayanto, F., Supriyatna, N., Dirhamsyah, M. 2010. Where the first wave arrives in minutes: Indonesian lessons on surviving tsunamis near their sources, IOC Brochure 2010-4, 28 pp., U. N. Educ., Sci., and Cultural Organ., Paris.

\section{HASIL DISKUSI}

\section{Pertanyaan}

1. Retno Purwanti (Balai Arkeologi Palembang)

Adakah catatan Gunung Dempo dan Ranau Erupsi? Apakah ada catatan Gempa bumi di Sumatera bagian selatan yang berdampak pada manusia?

2. Chr. Sonny Wibisono, M.A., DEA (Pusat Penelitian Arkeologi Nasional) Kami sedang mencari pelabuhan dari Tarumanegara, yaitu Teluk lada dan di mana pelabuhan Tarumanegara pada saat itu. Adakah informasi yang bapak ketahui?

\section{Arif Budiman (MAN 1 Jakarta)}

Bagaimana caranya agar kebudayaan Jawa itu tidak selalu diidentikkan dengan mistisisme, musyrik, dan sebagainya? Apa arti angka-angka 100, 200, 500 kaitannya dengan kejadian bencana? Naskah-naskah cerita atau khasanah lokal apa saja yang dapat dijadikan rujukan kebencanaan yang terjadi di masa lampau? 


\section{Jawaban}

1. Catatan tertulis tentang erupsi Gunung Dempo dan Gunung Ranau di Masa Prasejarah dan Masa Klasik tidak atau belum ditemukan. Catatan tertulis yang ada adalah tentang erupsi pada Masa Kolonial-Modern setelah tahun 1800 yaitu berupa aktivitas-aktivitas erupsi dengan VEI 2. Hasil penelitian geologi terkait erupsi kedua gunung pada kala Plistosen akhir hingga Holosen juga belum banyak. Salah satu rekaman geologi mengungkap erupsi Gunung Ranau pada sekitar 33 ribu tahun lalu.

2. Saya tidak mempunyai informasi detil tentang Pelabuhan Kerajaan Tarumanegara. Tapi kita tahu adanya tinggalan Tarumanegara berupa kompleks Percandian Batujaya di Karawang. Lokasi percandian ini saat ini berada sekitar 6-7 km dari garis pantai saat ini, dibangun di lingkungan rawa di sepanjang sungai-sungai. Posisi kompleks percandian saat ini dari garis pantai mengindikasikan majunya garis pantai dengan sangat cepat, tapi apakah hal ini memang yang terjadi belum diketahui dengan pasti. Boleh jadi juga, sejak semula kompleks percandian memang dibangun jauh dari pantai di dekat pusat hunian atau kerajaan, serupa dengan kompleks Percandian Muara Jambi atau Bumiayu.

3. Agar sebuah budaya tidak diidentikkan dengan hal-hal mistik, musyrik maka budaya itu perlu dipahami intisari pesan yang ada di dalamnya dan kemudian direvitalisati maknanya sesuai dengan pemahaman budaya kekinian masyarakat yang basisnya adalah logika. Oleh karena itu, penelitian multi dan intra disiplin tentang asal-usul budaya perlu dilakukan. Yang perlu kita pahami, prinsip dasar kerja sains yaitu "teliti" sebenarnya sudah digunakan oleh masyarakat di segala jaman untuk menjelaskan fenomena alam yang mereka hadapi. Fenomena alam dari waktu ke waktu selalu sama, namun penjelasan terhadap fenomena itu dari masa ke masa berbeda-beda sesuai dengan kepercayaan dan agama yang ada. Sebuah budaya pada dasarnya adalah rekaman dari respon masyarakat terhadap fenomena-fenomena di lingkungan hidupnya. Maka dengan membongkar sebuah budaya kita akan dapat mengungkap fenomena-fenomena yang memicu munculnya budaya itu. Selanjutnya kita bisa memberikan makna baru terhadap budaya itu sesuai dengan budaya masa kini. 